\title{
A scoping review of initiatives to reduce inappropriate or non-beneficial hospital admissions and bed days in people nearing the end of their life: much innovation, but limited supporting evidence
}

Ros Taylor ${ }^{1}$, Jonathan Ellis ${ }^{1}$, Wei Gao ${ }^{2}$, Liz Searle ${ }^{3}$, Kate Heaps ${ }^{4}$, Robert Davies ${ }^{5,6}$, Claire Hawksworth ${ }^{5}$, Angela Garcia-Perez ${ }^{5}$, Giles Colclough ${ }^{7}$, Steven Walker ${ }^{5,6^{*}}$ (i) and Bee Wee W, $^{8,9}$

\begin{abstract}
Background: Hospitalisation during the last weeks of life when there is no medical need or desire to be there is distressing and expensive. This study sought palliative care initiatives which may avoid or shorten hospital stay at the end of life and analysed their success in terms reducing bed days.

Methods: Part 1 included a search of literature in PubMed and Google Scholar between 2013 and 2018, an examination of governmental and organisational publications plus discussions with external and co-author experts regarding other sources. This initial sweep sought to identify and categorise relevant palliative care initiatives. In Part 2, we looked for publications providing data on hospital admissions and bed days for each category.

Results: A total of 1252 abstracts were reviewed, resulting in ten broad classes being identified. Further screening revealed 50 relevant publications describing a range of multi-component initiatives. Studies were generally small and retrospective. Most researchers claim their service delivered benefits. In descending frequency, benefits identified were support in the community, integrated care, out-of-hours telephone advice, care home education and telemedicine. Nurses and hospices were central to many initiatives. Barriers and factors underpinning success were rarely addressed.
\end{abstract}

Conclusions: A wide range of initiatives have been introduced to improve end-of-life experiences. Formal evidence supporting their effectiveness in reducing inappropriate/non-beneficial hospital bed days was generally limited or absent.

Trial registration: N/A

Keywords: Palliative care, Home care, Hospital care, Nursing home care, Service evaluation, Supportive care

* Correspondence: steven.walker@stgmed.com

${ }^{5}$ Stgilesmedical Ltd, The Vestry House, St Giles High Street, London WC2H

$8 \mathrm{LG}, \mathrm{UK}$

${ }^{6}$ Stgilesmedical GmbH, Berlin, Germany

Full list of author information is available at the end of the article

(c) The Author(s). 2020 Open Access This article is distributed under the terms of the Creative Commons Attribution 4.0 International License (http://creativecommons.org/licenses/by/4.0/), which permits unrestricted use, distribution, and reproduction in any medium, provided you give appropriate credit to the original author(s) and the source, provide a link to the Creative Commons license, and indicate if changes were made. The Creative Commons Public Domain Dedication waiver (http://creativecommons.org/publicdomain/zero/1.0/) applies to the data made available in this article, unless otherwise stated. 


\section{Background}

For patients, being in a hospital bed during the last weeks of life when they have no medical need or desire to be there is distressing and expensive [1-3]. Patients with incurable conditions are often admitted with little or no benefit to their clinical state [4]. While there may be mitigating circumstances, e.g. providing respite care, such inappropriate or non-beneficial use of resources may be regarded as a failure of the system [4-6]. This problem is likely to intensify as the number of people dying increases along with their age at death [7]. Also, people are living longer with multiple morbidities, necessitating additional resources [8]. Several reports have sought to address inadequacies in care provision [9-13].

Place of death is important for some patients and their families. Whereas the literature suggests many people want to die at home, this preference may vary with age, disease state and care needs [14, 15]. For many patients, their eventual place of death may not match individual preferences [16]. An international comparison found that more than $50 \%$ of deaths occur in hospital, ranging from $78 \%$ in Japan to $20 \%$ in China [17].

Dying in hospital is likely to be the costliest component of care in the final months of life [18]. Data from England collected between April 2009 and March 2012 showed that, on average, adults in the last year of life experienced 2.3 hospital admissions accounting for 30 bed days, with $57 \%$ of usage occurring in the last 3 months of life [19]. The costs of UK hospital admissions in 2011 for adults in the last year of life was estimated to have been $£ 1.3$ billion, with a report from the Netherlands suggesting that this cohort was responsible for $10-12 \%$ of total health expenditure [6, 20].

Such data has caused some to speculate that the economic burden could be minimised by introducing initiatives designed to avoid or shorten unnecessary admissions at the end of life $[6,21]$. An example of what could be achieved comes from a retrospective analysis of 483 patients who died within 1 year of admission to two UK hospitals. This analysis concluded that 35 admissions were potentially avoidable and could have saved the hospitals $£ 5.9$ million per year [5]. Had hospital stays been shortened across all 483 patients by $14 \%$, the savings would have been substantially greater, at an estimated $£ 47.5$ million. Others consider these figures to be an underestimate, suggesting that $20-40 \%$ admissions in the last year of life could be avoided [22, 23]. It is acknowledged that shifting the burden of care would result in increased family and community care costs [24].

One problem is the lack of accurate data to compare the costs of delivering palliative care across different settings $[6,18]$. In the United States, Medicare and Medicaid data show that costs vary widely but there are advantages in the form of actual reimbursement by the insurer [18]. In comparison, the widely quoted UK target price for one specialist palliative care National Health Service (NHS) bed day of around $£ 412$ represents the national tariff paid by a commissioner, rather than the actual cost to the healthcare provider $[18,25]$. Estimates for community and hospice costs are generally considered even less reliable. A more useful proxy measure for the success of a palliative care innovation, may be a reduction in hospital bed days when hospital admissions are not medically indicated or in accordance with patients' or families wishes.

There are many reports of palliative care initiatives worldwide that could have an impact on hospital admissions and bed days. These initiatives often involve the hospice movement, which has shown itself proactive in developing new services. Feedback from specialists suggests that the range of services that could benefit patients and their families is not widely appreciated outside of senior palliative care circles. Similarly, limited information is available regarding the effectiveness of many initiatives. As discussed, measuring resource usage may be preferable to estimating costs as an outcome measure. Consequently, the two main aims of this research were to identify initiatives which may avoid or shorten unnecessary or unwanted hospital admissions at the end of life and analyse their success in terms of a reduction in bed days. Data from this study will inform the ongoing HOspice-Led Innovations Study To Improve Care (HOLISTIC) project [26].

\section{Methods}

This study comprised two parts. The first part sought to identify and categorise initiates which may influence hospital admissions and bed days. The second part explored objective reasons for success of the intervention by reducing bed days and how initiatives might be upscaled or transferred elsewhere. Both parts involved a multiple author search of articles in English in PubMed and Google Scholar between 1st January 2013 and 31st November 2018, an examination of governmental and organisational publications, a hand-search of documents looking for additional information, and discussions with external and co-author experts regarding other sources of information.

\section{Part 1}

We sought to identify and classify established initiatives which were considered likely to have a quantifiable impact on hospital admissions and bed days at the end of life. Search terms included 'avoidable/inappropriate hospital admissions', 'cost/economics at the end of life' or 'hospital discharge'. Our initial search resulted in the identification of ten initiatives grouped under three broad headings. 
Part 2

A more detailed literature search was conducted separately for each initiative identified in Part 1, using the search terms 'end-of-life', 'palliative care', 'hospital bed days', 'hospice', 'nursing home', 'reduction', 'decrease', 'innovation', 'hospital admission', and 'length of hospital stay'. The contents of these publications were hand searched for by other relevant data sources. Only those presenting data on hospital utilisation and/or duration of stay were included. Hospital utilisation was defined as admission to either hospital and/or emergency departments, whatever the cause, in patients considered to be in the last year of life. Further exclusions were made if the study language was non-English and/or a paediatric population was included. We also removed any studies where the palliative intervention was considered routine practice. After the selected publications were examined, the methodology was refined to seek information on the steps required for initiatives' introduction, sustainability and upscaling.

\section{Results}

\section{Part 1}

A total of 1252 abstracts were reviewed by one author, resulting in the identification of ten categories of initiatives grouped under three broad headings (Fig. 1, Table 1): 1;'Facilitating entry into the hospice and community care system' [27], 2a-2 g; 'Preventing admission' [28-74] and 3a\&3b; 'Facilitating discharge' (Table 1) [56, 66, 72, 75-78]. Classification was reviewed by a second author. Because of variations in terminology used to describe similar activities and the multifactorial nature of some initiatives, a degree of judgement was required when determining which group the initiative should be assigned to. Differences of opinion were resolved by discussion among the authors.

\section{Part 2}

\section{Overview}

Fifty publications provided data on hospital utilisation and/or hospital stay. Selected publications often described initiatives with multiple components, resulting in them sometimes being included in more than one category. Studies were generally small and retrospective in nature. Most researchers claimed their services delivered benefits-in descending frequency order, these benefits were, palliative care support in the community (including hospice at home services), provision of integrated care, out-of-hours telephone advice, care home education and telemedicine. Nurses and hospices were central to many initiatives. Elements for success, sustainability, upscaling or adoption elsewhere were not generally addressed in the publications.

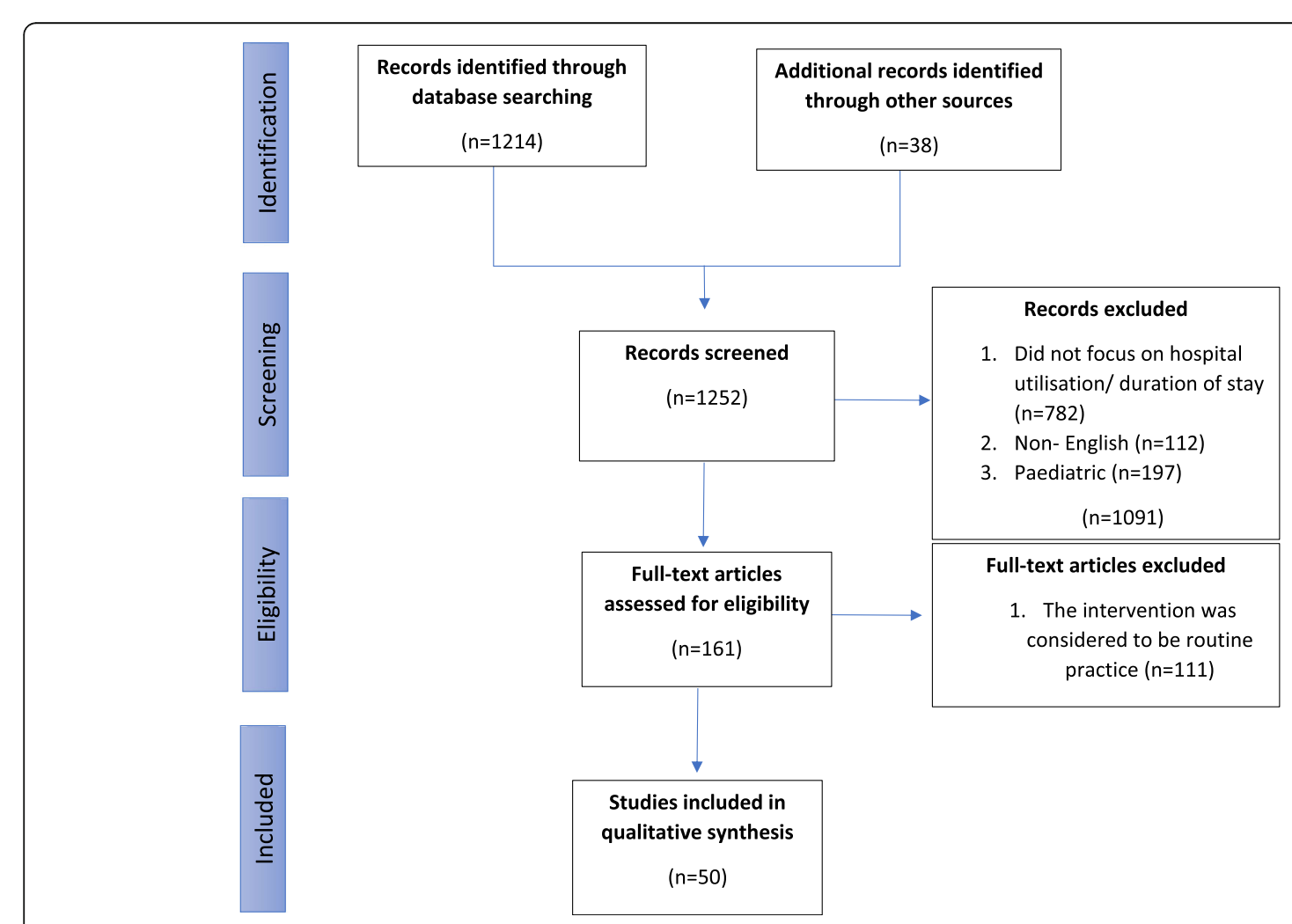

Fig. 1 PRISMA diagram 


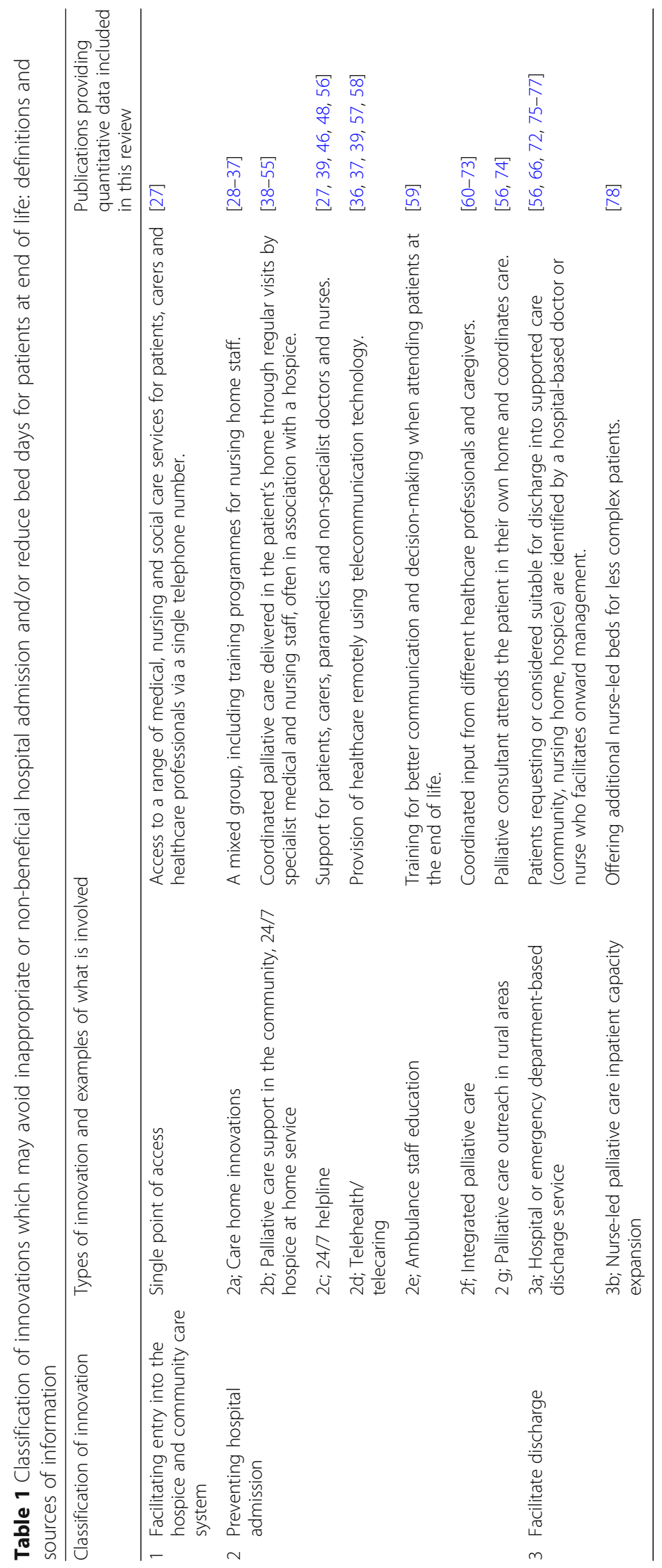




\section{Single point of access}

Several organisations offer Single Point of Access (SPA) services for people at the end of their life, but published evidence of the services' benefits is limited. The Sue Ryder organisation published an evaluation report of a pilot initiative, 'Partnership for Excellence in Palliative Support' (PEPS) [27]. PEPS is a 24-h telephone SPA service bringing together 15 organisations across East England, UK, with senior nurses as the first point of access.

During the pilot period, 1051 patients were registered with Partnership for Excellence in Palliative Support. The majority $(65 \%)$ who died, were supported to die at home, with only $11 \%$ dying in an acute hospital. Information from a sample of patients was compared with hospital activity data sets before and after registration and suggested that the introduction of a Single Point of Access service could result in $30 \%$ fewer admissions, a $30 \%$ shorter stay and cost reductions of around $£ 300$ per admission.

\section{2a; care home innovations}

Care home residents at the end of their life are sometimes transferred to hospital when another course of action might be more appropriate [1], possibly due to a knowledge gap among all grades of care home staff which could be addressed by additional training. The problem was explored in three studies using a mixed-methods approach (Table 2) [28-30] or quasi-experimental design [31] or as part of a randomised controlled trial [32]. Training varied in terms of duration, frequency and who delivered it. Common topics were, recognition of the end of life, advance care planning, optimising communication with residents and their families and documenting changes in patient preferences and condition.

Staff education was generally linked to a reduction in hospital admissions or a shorter length of hospital stay. Garden et al., for example, reported a 55\% decrease in admissions compared to baseline, 3 years after implementation [28]. Livingston et al., found that the average number of days spent in hospital in the last 3 months of life decreased from four to 1.25 days [29]. Chapman et al., reported a 3.22-day decrease in length of stay, equating to a $67 \%$ reduction in bed days for residents involved in the intervention, but having no effect on the number of admissions [31]. Other demonstrable benefits, were an increased number of deaths in the care home compared with the hospital [29], and care home staff feeling 'uplifted' and 'empowered' as a result of the intervention [30].

These favourable results are at odds with the findings of a randomised US study designed to evaluate the effects of the high-profile 'Interventions to Reduce Acute Care Transfers' (INTERACT) quality improvement programme [33]. While there was a trend in favour of additional staff training aimed at improving care at the end of life compared with the pre-intervention period, Kane et al., found no significant difference in admission rates between nursing homes randomised to receive INTERACT training and a control group [32].

Other initiatives have been introduced to support care home residents, such as the "Enhanced Health in Care Homes Vanguard' programme in the United Kingdom. While generally considered beneficial, these initiatives' effect on hospital admissions has been variable. One simple initiative, the introduction of 'red bags' containing all relevant health-related paperwork and medication that travel with the patient, helped simplify hospital transfers and reduced length of stay for residents in Sutton from a local average of 14 days to 9.2 days [34]. Meanwhile, the introduction of multidisciplinary teams in Newcastle and Gateshead saw an increase in nonelective admissions, possibly related to increased symptom recognition [35]. A Vanguard project in Airedale that implemented telemedicine consultations for care home residents showed a 15\% decrease in emergency admissions for homes that infrequently used the service, compared with a $10 \%$ increase for homes classified as high usage [36]. Also, a prospective observational study in Massachusetts care homes demonstrated that a group receiving telemedicine support, saw greater cost savings and hospitalisation reduction than the control group, especially where there was active engagement with the project [37].

\section{2b; palliative care support in the community}

We identified 18 studies that included a focus on the impact of palliative care support in the community (e.g., hospice at home services) on hospital utilisation (Table 3). As this is a heterogeneous group of initiatives which may include hands-on nursing care, specialist advice from multidisciplinary teams and emergency intervention, we have not sought to separate them. Ten studies were retrospective [39-41, 44, 47-51, 53], five were prospective cohort studies [38, 42, 52, 54, 55] and three were described as population studies $[43,45,46]$.

A proportion of studies concentrated on a specific disease area, including cancer [41, 43, 46, 47, 50, 51], chronic obstructive pulmonary disease [44], dementia [45] and heart failure [38]. The others included mixed diagnoses.

All studies reported that their programme had one or more benefits over standard care, notably a significant decrease in hospital admissions [38-41, 44, 46, 48-55].

Eight of ten studies examining the impact of palliative care support in the community on emergency department attendance observed a reduction in attendance for patients enrolled in the intervention group versus standard-care patients $[41-43,45-47,50,55]$. In one 


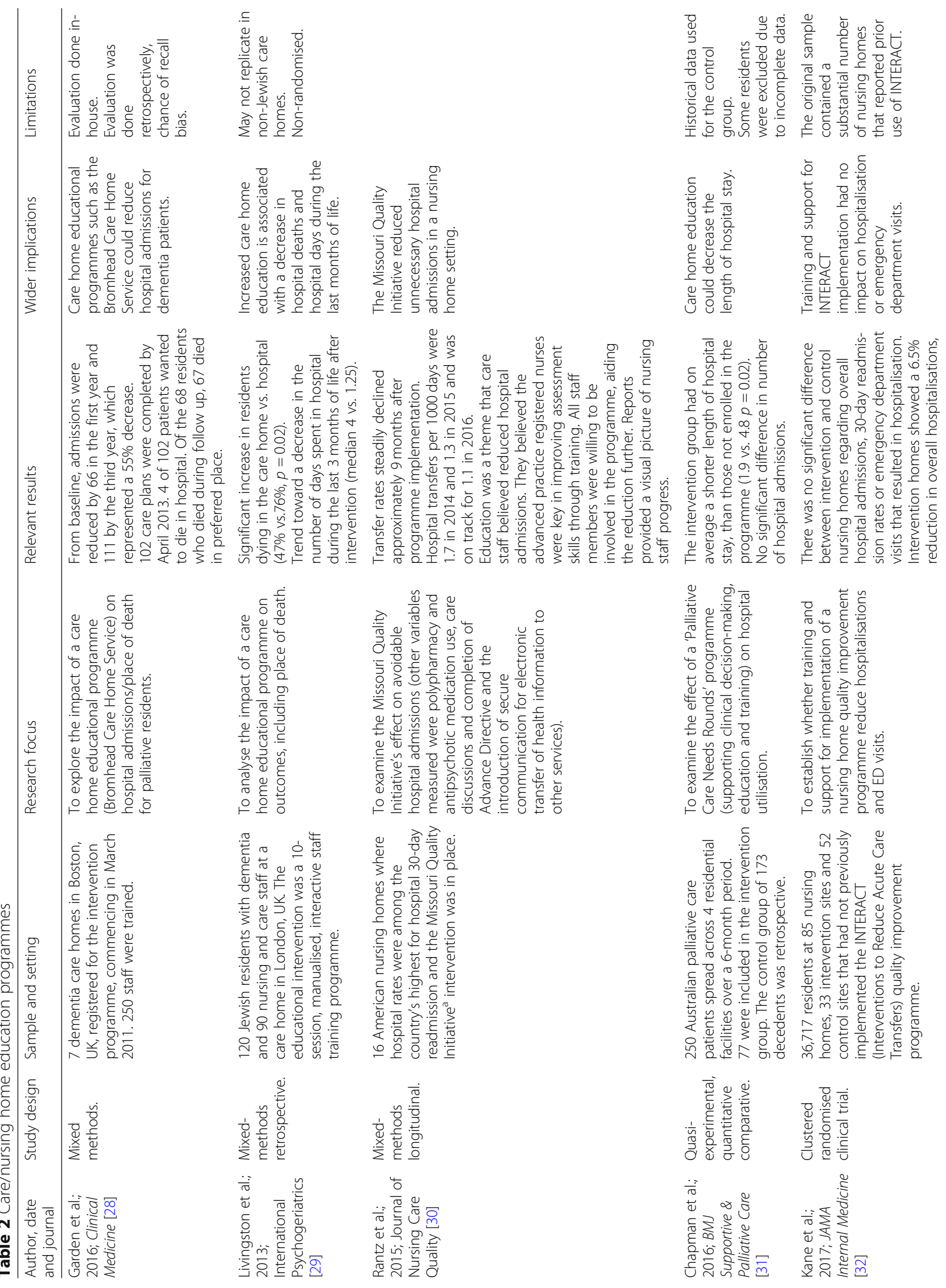




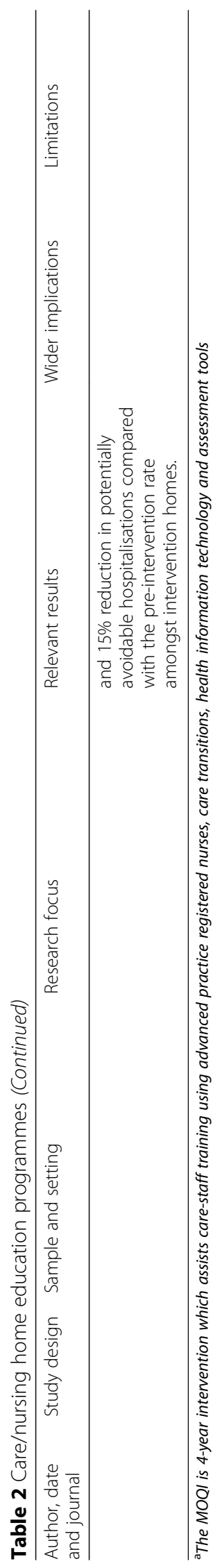




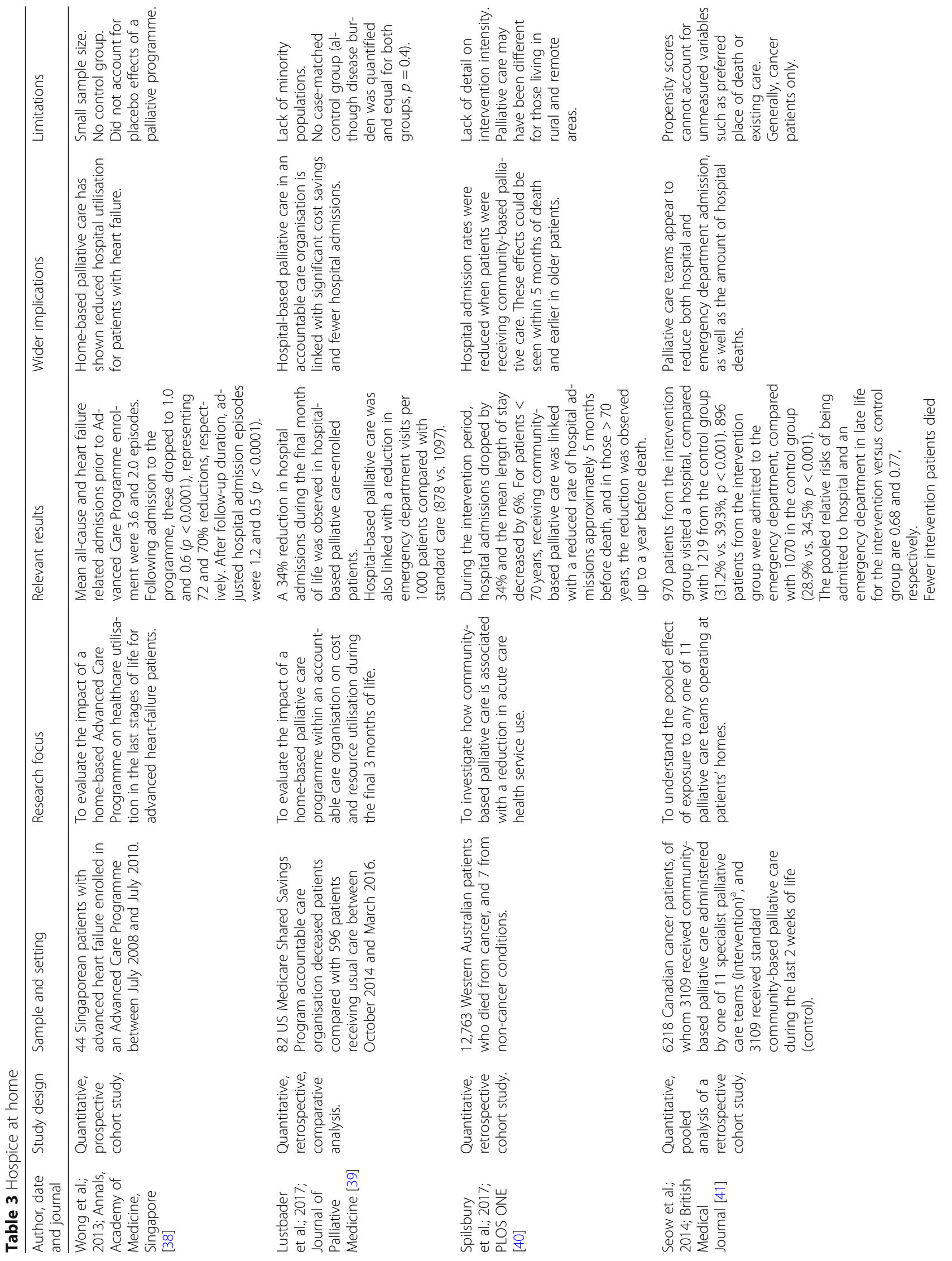




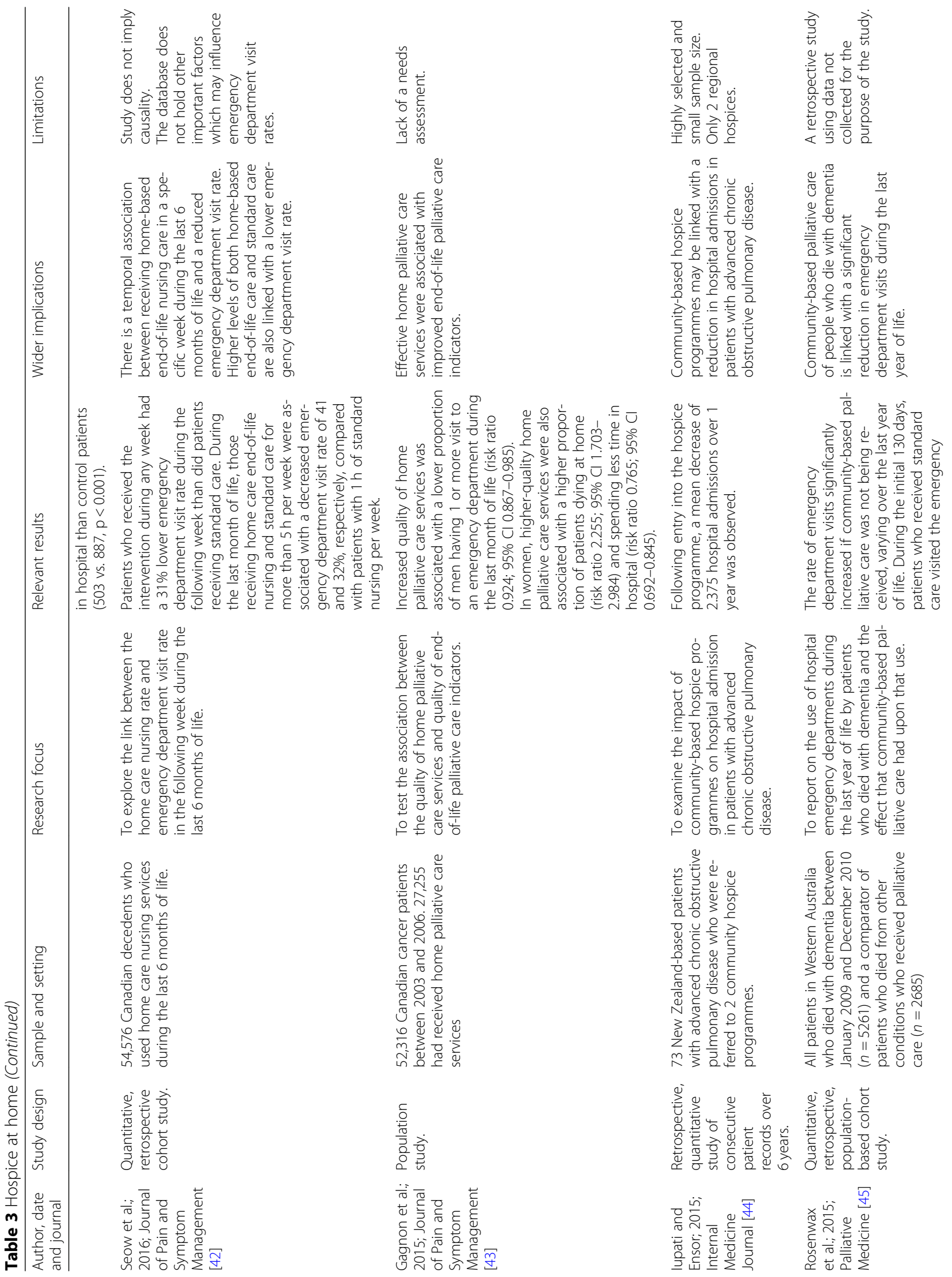




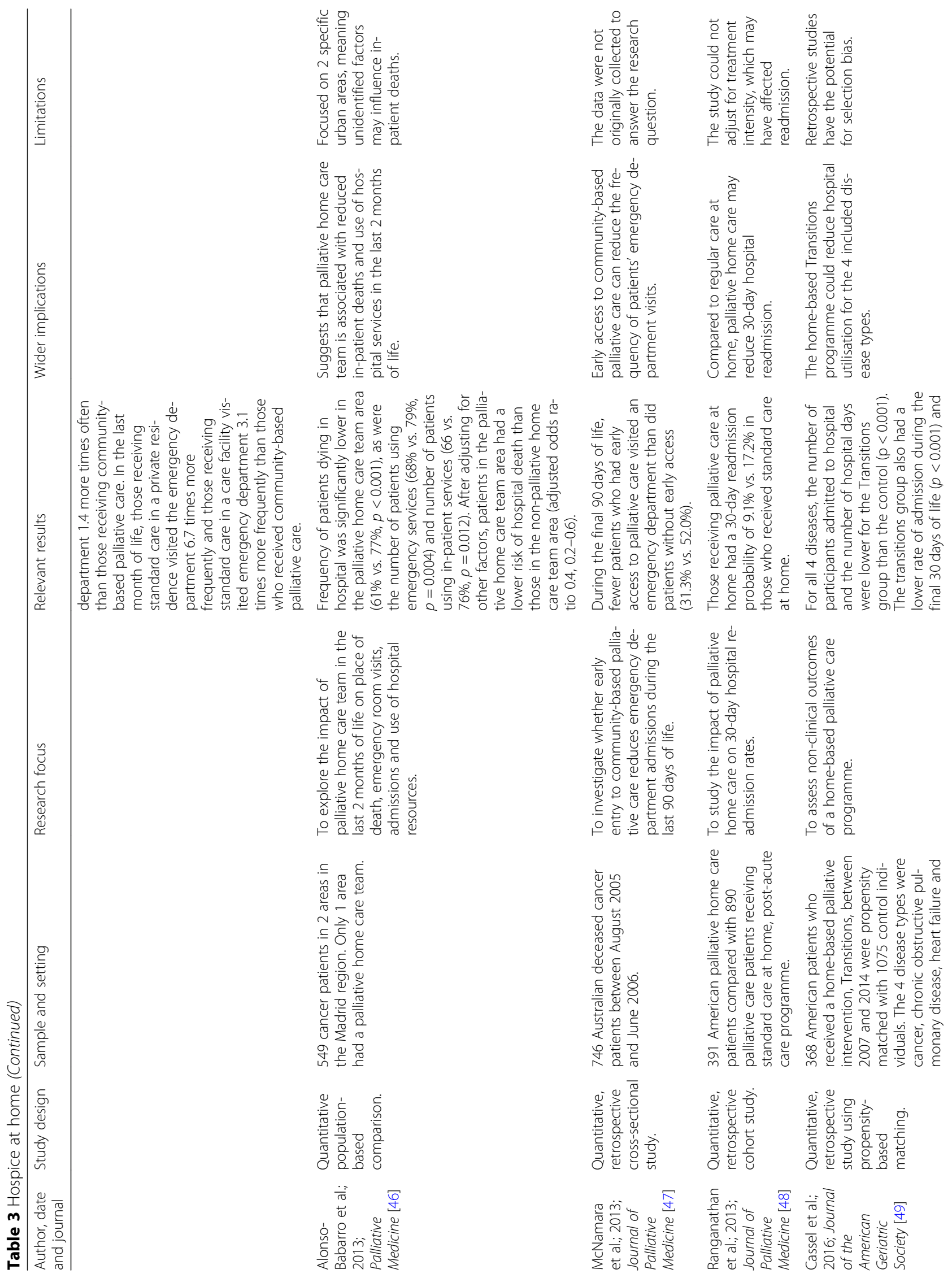




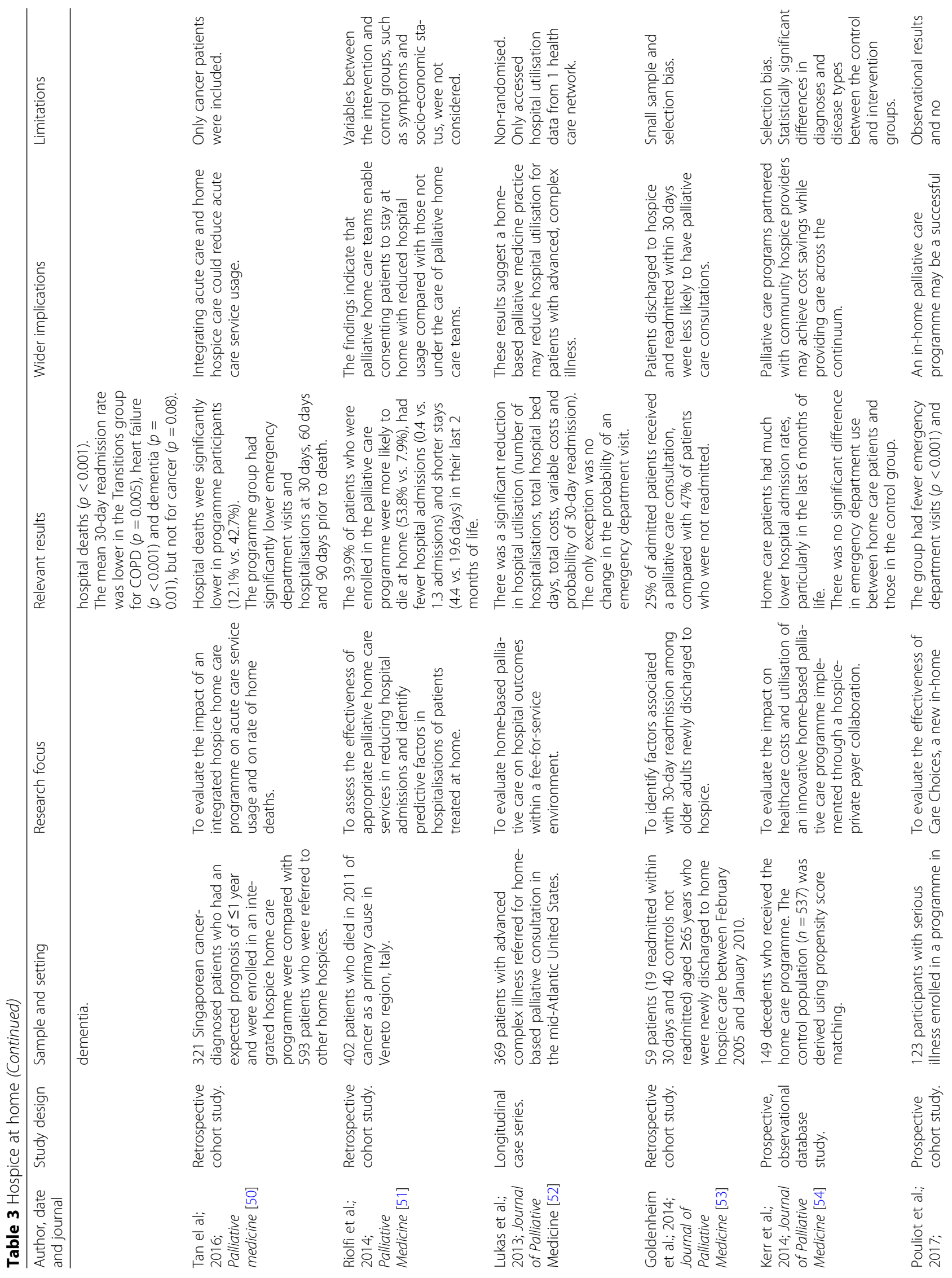




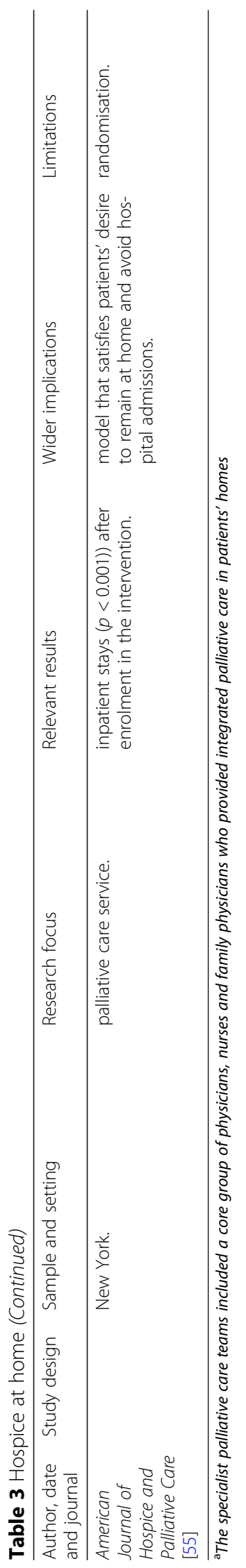


study, this effect was only seen in male patients, possibly because of greater provision of home palliative care services among those with prostate and colorectal cancer [43]. Two studies found no change in visits to the emergency department between intervention and control groups [52, 54].

Duration of hospital stay appeared to be shorter when patients were enrolled in one of the initiatives under examination [40, 43, 49, 51, 52], and fewer of those patients died in hospital [41, 43, 46, 49-51].

An editorial published in response to important findings on specialist palliative care teams' experiences in Ontario communities, points to what could be achieved elsewhere with additional support: 'If the associations reported by Seow and colleagues are causal, access to a palliative care team cuts hospitalisations by a third, use of emergency departments by a quarter, and risk of hospital death by a half, compared with usual care' $[41,79]$.

\section{$2 c$; out-of-hours telephone line}

Access to advice via an out-of-hours telephone line was often a feature in major initiatives, such as the PEPS programme [27]. Three retrospective, quantitative studies examined hospital admission and emergency department attendance $[39,48,56]$, and a fourth looked at 30day readmission rates [46] (Table 4). All were linked to a significant decrease in hospital utilisation. Lustbader et al., found that a home-based palliative care programme including an out-of-hours telephone line was associated with a $34 \%$ reduction in hospital admission and nearly 200 fewer emergency department admissions per 1000 patients during their final month of life [39]. The benefits of an out-of-hours telephone line were also observed by Ranganathan et al. [48]. Patients enrolled in the initiative being studied had a 30-day readmission probability of $9.1 \%$, compared with $17.2 \%$ in patients receiving standard care.

\section{2d; telemedicine/teleconsultation}

Two studies examining the value of telemedicine in care homes from UK and US perspectives are described in the care home initiative discussion above [36, 37]. Three additional studies attempted to analyse the influence of telehealth/telecaring on hospital utilisation among patients at the end of life (Table 5). Two were RCTs [57, 58], in which telehealth was the primary variable. The impact of both telehealth versus control, and early versus delayed use of telehealth on hospital utilisation were tested, with neither demonstrating a significant benefit. Interestingly, in Hoek et al.'s study, the mean Total Symptom Distress Score was higher in the intervention group at 12 weeks [57]. In contrast, a quantitative retrospective study where tele palliative consultations between patients and any healthcare team member were an essential part of a wider programme, witnessed a reduction in both hospital and emergency admissions [39].

\section{$2 e$; ambulance and paramedic education}

Ambulance and paramedical staff are often the first healthcare professionals to respond to a palliative care emergency outside of hospital. The situations they face are frequently distressing and confusing. Many feel ill prepared [59]. There is anecdotal evidence of additional palliative care training for ambulance and paramedical staff helping them make better decisions. Unfortunately, published peer-reviewed articles are lacking. Paramedic initiatives depend not only on training, but also on adequate resources to keep someone at home following an emergency call-out, which may limit ambulance initiatives' success.

\section{2f; integrated palliative care models}

Fourteen studies examined the use of integrated palliative care and its impact on hospital utilisation. Three of those studies were RCTs (Table 6) [60-73].

The components of care varied, with 12 studies concentrating on one disease type [cancer: seven [60-66], heart failure: two [67, 68], renal failure: one [69], chronic obstructive pulmonary disease: one [70], neurodegenerative disease: one [71]].

A study by $\mathrm{Wu}$ et al. examined the benefits of initiating palliative care consultations in emergency departments for patients suffering from a range of terminal diseases [72], while Desrosiers et al., reported on the value of a hospital-based palliative care service for patients with advanced organ failure in sub-Saharan Africa [73].

Overall, 11 studies found the initiative to be beneficial. In contrast, Ferrell et al., in a prospective quasiexperimental study, examined the value of an integrated care group for managing patients with non-small cell lung cancer (NSCLC; $n=272)$ versus standard care $(n=$ 219) [60].. No significant difference in unscheduled hospital admissions in the last 2 weeks of life was observed between the intervention and control groups.

Two RCTs painted a similar picture. Rogers et al., conducted a single-centre US study involving 150 patients with advanced heart failure. Subjects were randomised to either usual care $(n=75)$ or usual care plus nurseimplemented integrated palliative care $(n=75)$. While there were benefits in the intervention group in terms of quality of life, anxiety, depression, and spiritual wellbeing, there was no effect on rehospitalisation or mortality [67]. In a Danish study involving 340 cancer patients, Benthien et al., looked at the value of adding specialised palliative care and psychological interventions to standard care and found that the intervention group actually experienced more admissions [61]. These findings 


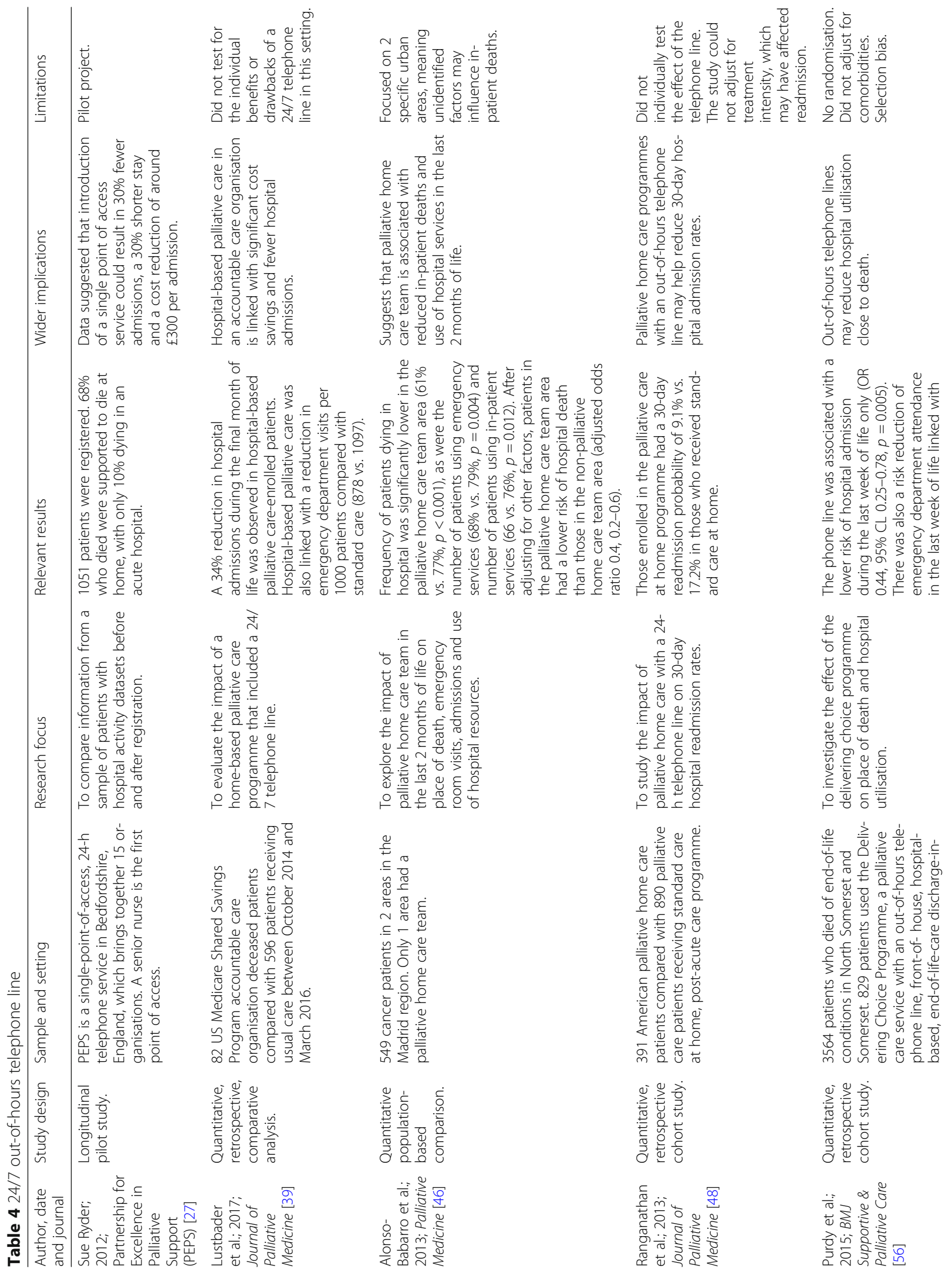




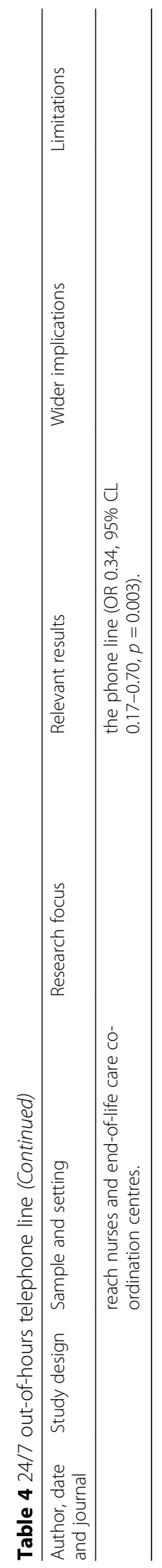




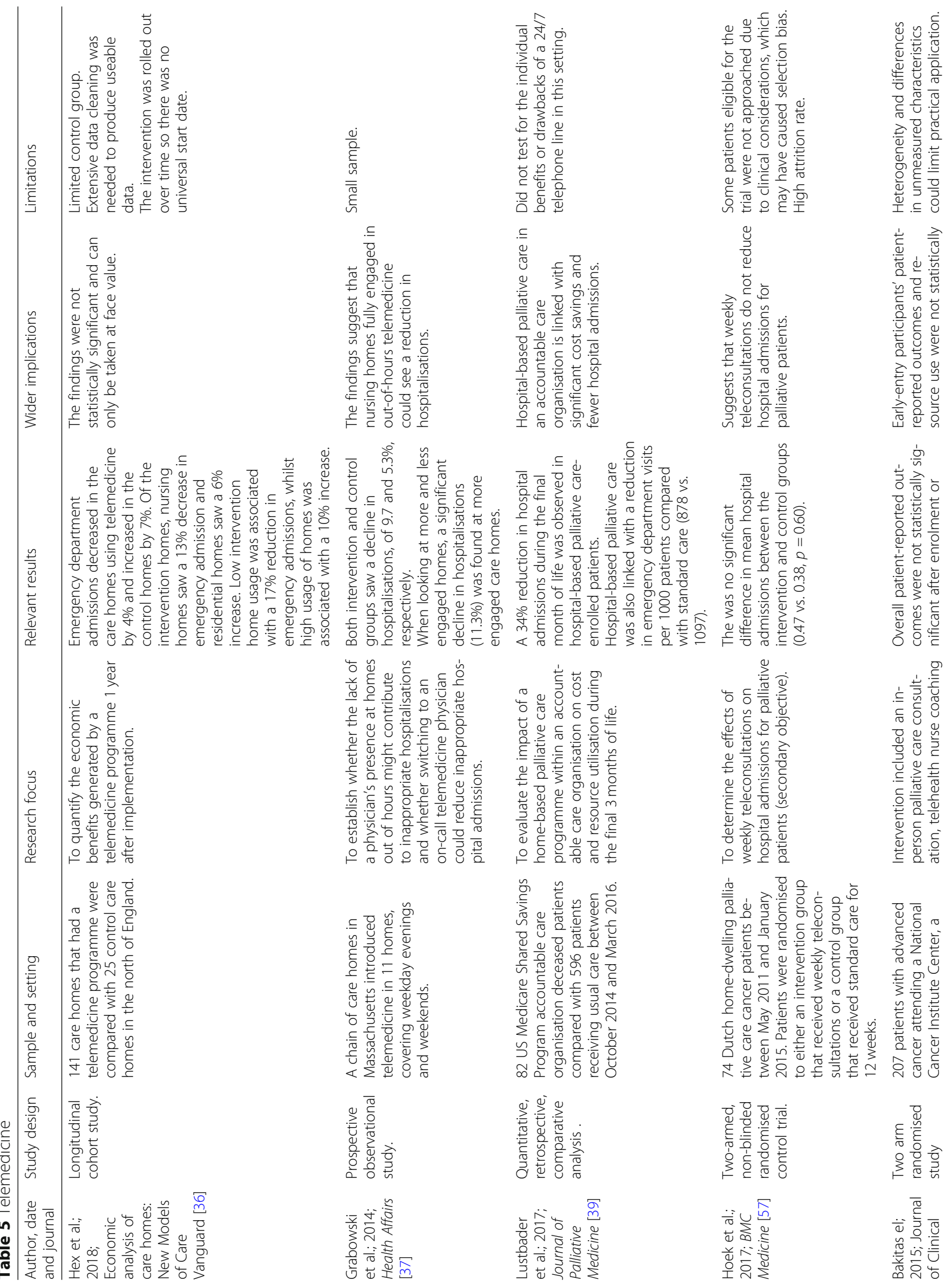




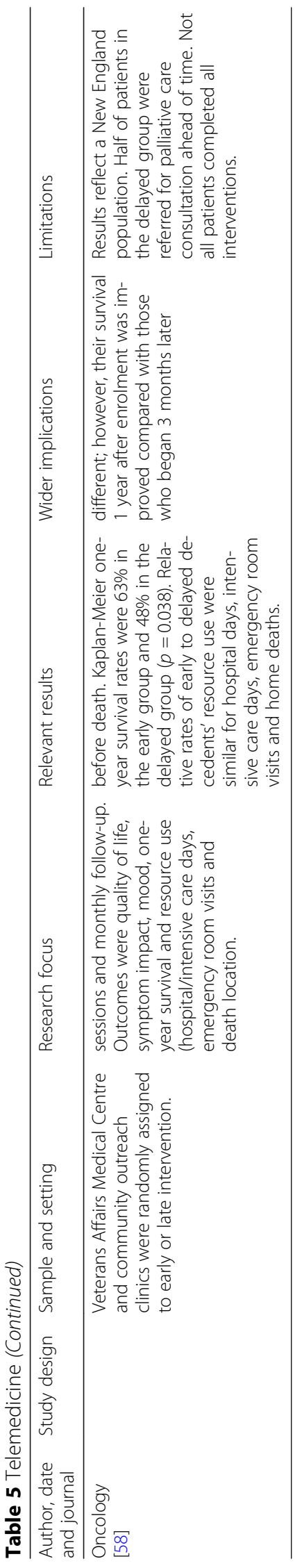




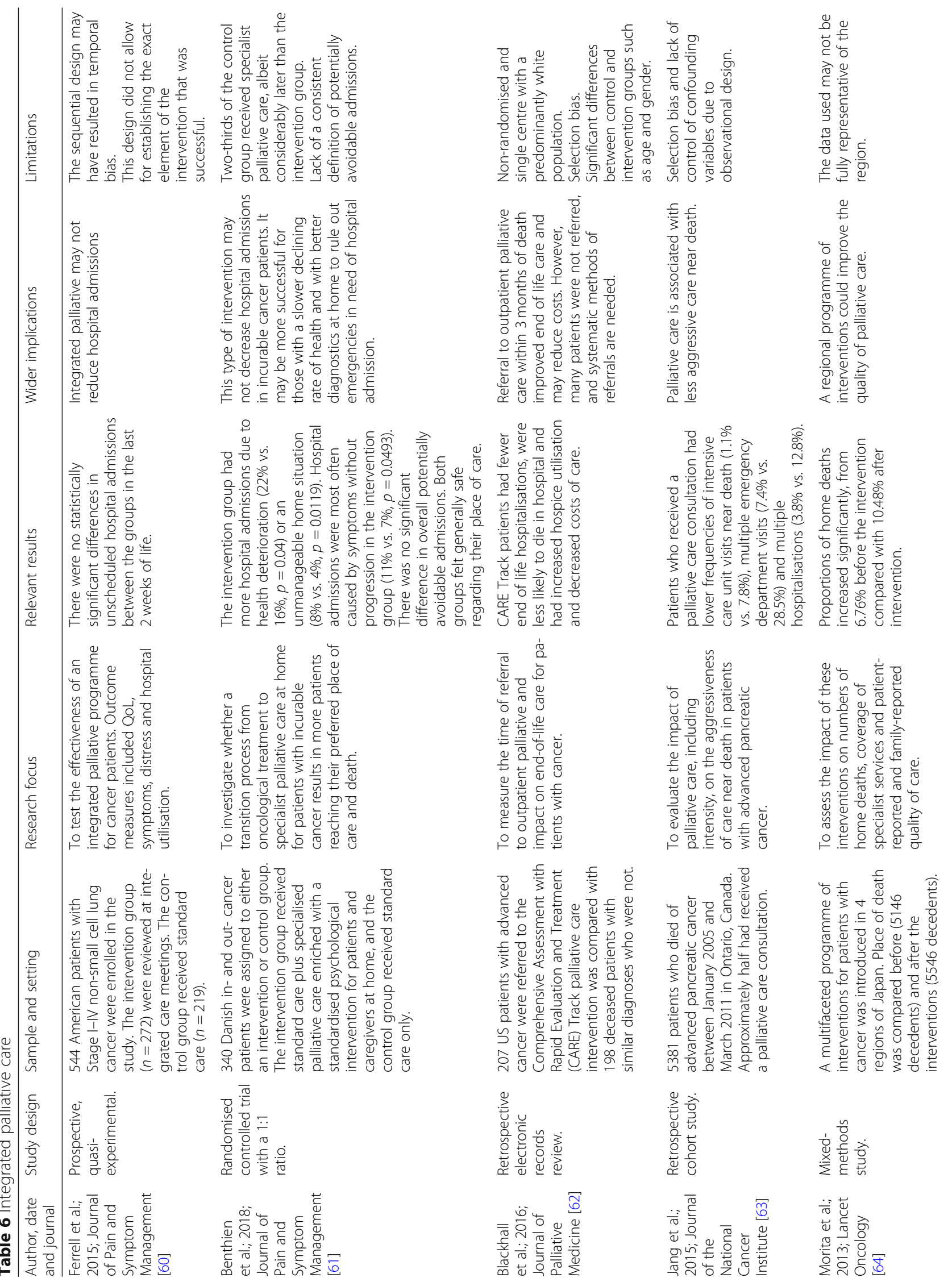




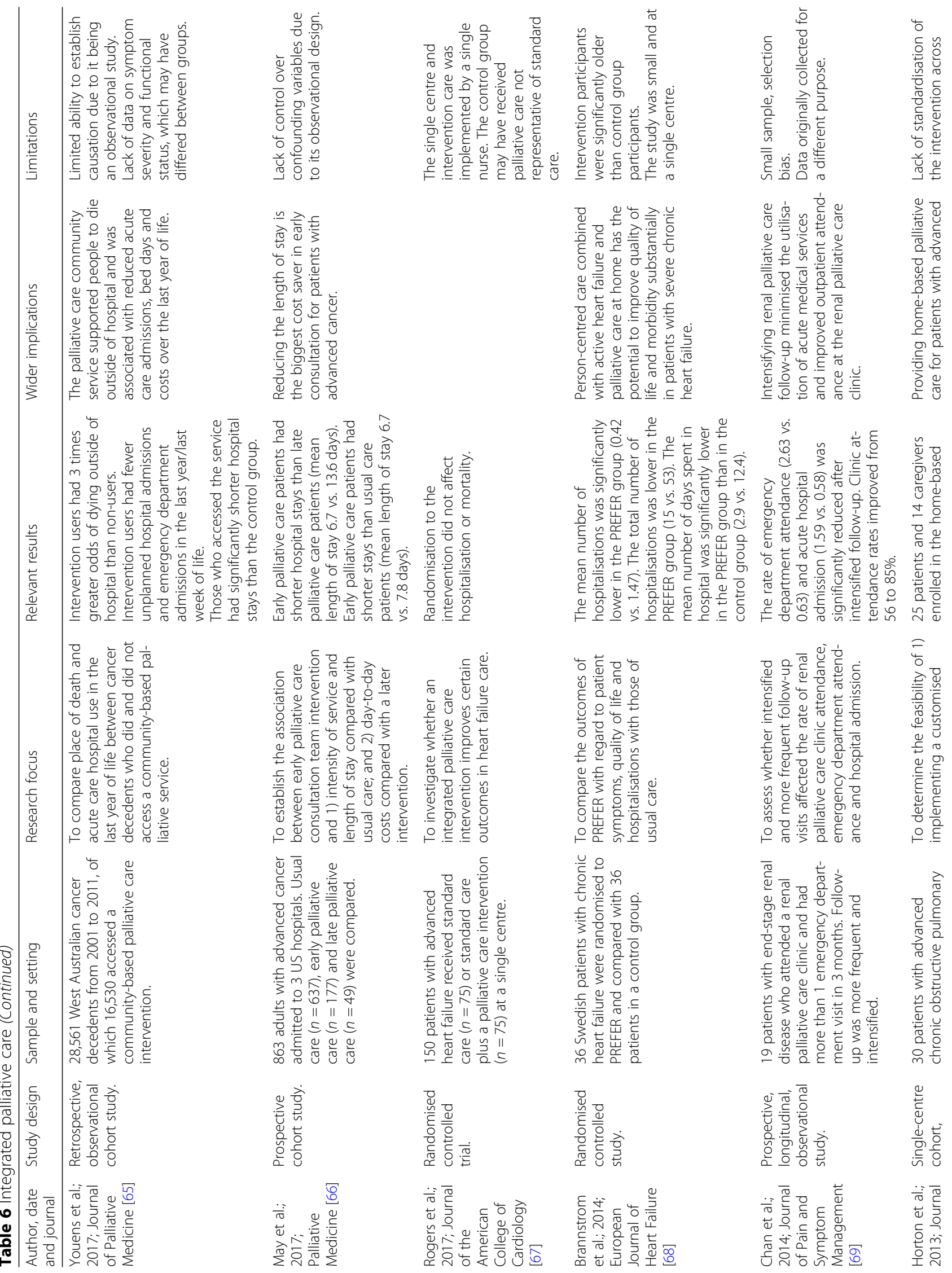




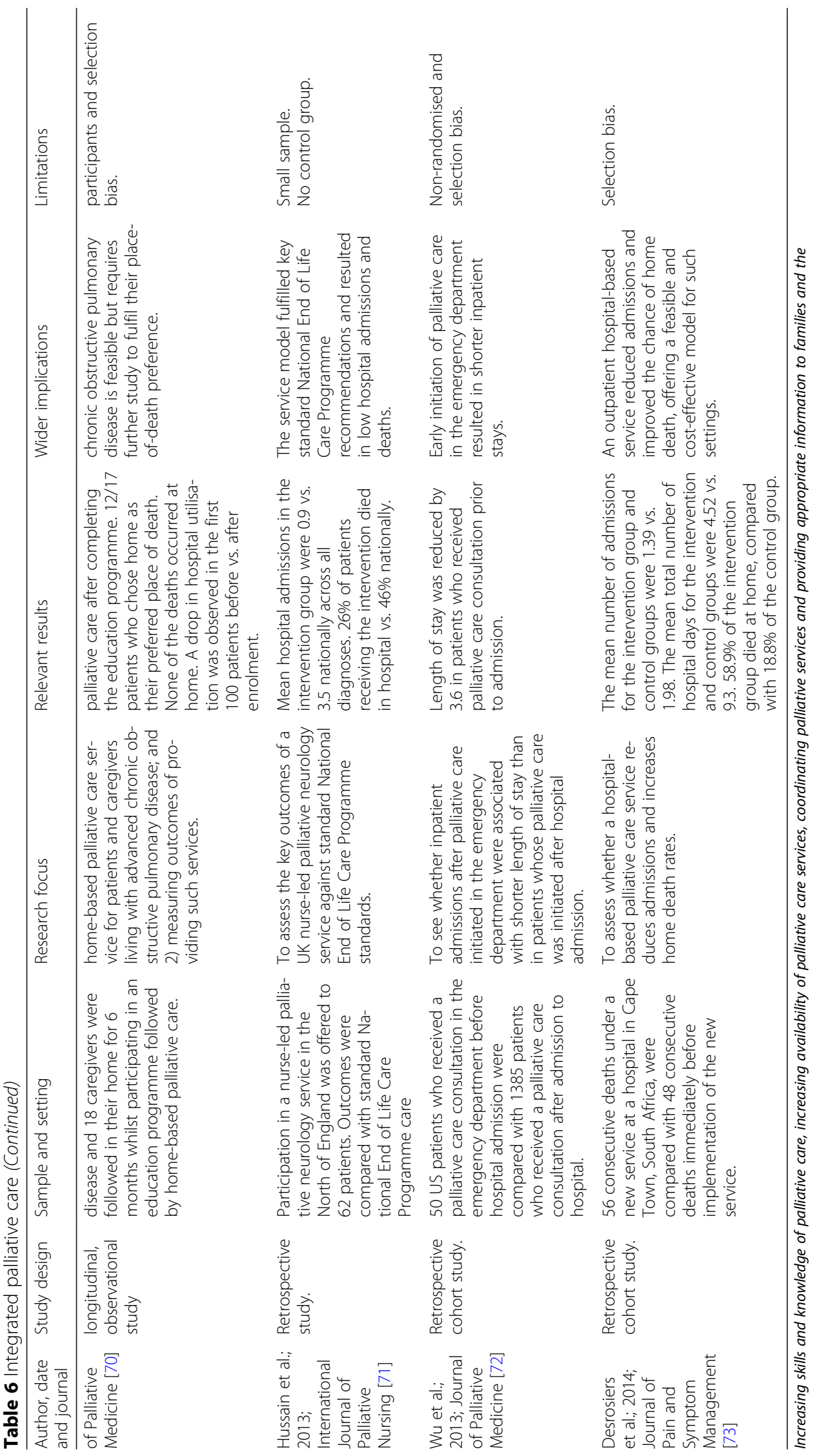


contrast with those of a smaller, single-centre Swedish RCT on chronic heart failure (Palliative advanced home caRE and heart FailurE care study; PREFER) [68]. Patients were randomised to an intervention group (usual care plus a person-centred palliative care programme ('PREFER', $n=36$ ), or a control group (usual care, $n=$ 36). Fewer hospitalisations and bed days were encountered in the PREFER group (15 hospitalisations, 103 days), than in the control group (53 hospitalisations, 305 days).

\section{2 g; palliative care outreach in rural areas}

Delivering palliative care to patients outside urban areas is a challenge. The 'Marie Curie Delivering Choice Programme ' consisted of several elements and was delivered in rural Somerset, England. In a quantitative retrospective cohort study [56], Purdy et al., investigated the effects of this initiative on place of death and hospital utilisation. Of 3564 patients who died of a chronic condition, 829 used the Delivering Choice Programme service. Users of the service were at least 30\% less likely to die in hospital, be admitted for an emergency or attend the emergency department than those who did not use the service. Readmissions after accessing the discharge in-reach service were low, at $6 \%$.

Evaluation of a nurse-led navigation service to provide palliative care to older patients in rural Canada was similarly beneficial [74]. Over a two-year period, 25 adult patients and 11 family members living with deteriorating chronic illness received biweekly visits. Support included symptom management, education, advance care planning, advocacy, help with financial matters and psychosocial help. Participants were able to die in their preferred location and emergency room attendance was minimal and largely unpreventable.

\section{3a; innovations supporting early hospital discharge}

The potential benefits of initiating palliative care consultations in emergency departments have been referred to above, with $\mathrm{Wu}$ et al., demonstrating a significantly shorter patient stay compared with a control group, of 3.6 days [72]. The study by Purdy et al., also included two 'front-of-house' hospital-based discharge nurses whose role included identifying patients wanting a nonhospital death and facilitating their transfer back home [56]. Additionally, the benefits of an early palliative care inpatient consultation in terms of shorter hospital stays were demonstrated by May et al., in a prospective multisite cohort study [66]. May et al., also found that there were significant cost savings (63\%) linked with a shorter length of stay. Further, beneficial effects of an inexpensive quality-of-life checklist on readmission rates were investigated by means of a prospective cohort study [75]. The researchers compared outcomes among 48 intervention subjects and 48 controls admitted to hospital with heart failure in Michigan. After adjusting for descendants, there was a significant difference in 30-day readmission in favour of the intervention group ( $2 \%$ vs. 20\%.)

There is evidence to support the value of a hospitalbased palliative care programme. In a retrospective study, Hua et al., found that patients in the intervention and control group experienced the same length of stay ( 6 days) but patients in the intervention group were $46 \%$ more likely to be discharged to a hospice [76]. These findings are supported by those of Horton et al. [77].

\section{3b; nurse-led inpatient initiatives}

It is increasingly common for nurses to lead end of life care services, of which this review identified several examples [27, 74]. St Gemma's Hospice in Leeds, England, supported by The Health Foundation, has taken this further by introducing four nurse-led beds for patients with less complex medical needs [78]. Data from this pilot project suggests that nurses can safely deliver end of life care, and during the study period, 50 patients achieved their preferred place of death, resulting in a reduction in hospital deaths and an estimated saving of 132 bed days.

\section{Discussion}

\section{Main findings}

This research has identified a wide range of initiatives which may affect inappropriate or non-beneficial hospital utilisation for people nearing the end of their life. Generally, interventions led to a reduction in emergency attendance and hospital bed days. A minority of studies found no benefits in the intervention group, while others showed an increase in hospital utilisation. Most publications reported retrospective studies with data originating from one centre. Research was focused on palliative care support in the community, hospice at home services, integrated care provision, out-of-hours telephone advice, care home education and telemedicine. Nurses and hospices were central to many innovations. To our knowledge, this is the first attempt at an overview.

\section{What this study adds}

Consistent evidence was found of reduced hospital utilisation, after palliative care was introduced to the community programme, with several population-based studies benefitting from larger sample sizes (6000 to > 50,000 patients) [40-43]. This topic has been the subject of earlier reviews [80, 81]. In contrast, other interventions' findings were mixed. Whereas improved nursing home education was found to be beneficial in four studies, it was not supported by a large RCT examining the INTERACT programme in the United States [32]. There was some support for telehealth, but again, this 
was not confirmed to reduce utilisation in two RCTs $[57,58]$. We found little published evidence supporting initiatives such as palliative care training for ambulance staff or SPA services. One leading palliative care centre in the United Kingdom, known to the authors, is convinced as to the value of its SPA but there has been no robust evidence confirming a potential benefit published so far.

Two 'negative' RCTs require additional comment. In Hoek et al.'s study, the mean Total Symptom Distress Score was greater in the intervention group after the trial period [57]. Contributory factors may include the study's small number of participants, the teleconsultation group's higher baseline score, and a 'nocebo' effect, where symptoms become the consultation's prime focus. Also, in their study, Benthien et al. [61], found that the intervention group had a higher admission rate. The researchers suggested that carers' closer observation led to more symptoms being identified, and the publicly financed Danish healthcare system-where reimbursement is based on performance-may encourage hospital utilisation.

Relatively few publications examined initiatives designed to facilitate patient discharge from hospital once they had been admitted. The little evidence of these initiatives' effects suggests that early specialist palliative care provided by doctors and nurses can reduce hospital bed days [56, 66, 72, 75]. There may even be benefits to starting such conversations in the emergency department [72]. Experience of healthcare staff, suggests that there are often multiple administrative issues delaying patients' return home, so simple initiatives such as using an accompanying 'red bag' with patients' details and medication may be helpful [34]. Only one study found that hospital-based palliative care increased the chance of discharge to a hospice [76].

As our research progressed, it seemed beneficial to investigate the link between outcomes and critical factors for introduction and sustainability, and how initiatives might be successfully upscaled or adopted elsewhere. This investigation has not been possible with the current data. The publications we examined, generally describe initiatives and outcomes but do not provide extensive detail. We suspect that contributory factors may include local need, leaders' and team members' enthusiasm and supportiveness, and funding.

\section{Study strengths, weaknesses and limitations}

Our research provides a broad overview of current activity outside of hospitals and hospices, which may reduce unnecessary and inappropriate hospital attendance and admissions, and bed days. Such evidence could be of benefit for those seeking to develop new services and obtain sources of funding. The robustness of evidence examined in this review was, however, limited. Also, studies generally failed to identify whether reducing admissions was in accordance with the patient or their families wishes i.e. not all days spent in a hospital bed were 'bad, unnecessary or unwanted.

Undertaking palliative care research is difficult, despite many patients' willingness to participate [82]. It is therefore unsurprising that we only identified six relevant RCTs. Most of the data was collected retrospectively, risking recall bias. Also, many concentrated on one disease area, notably cancer, which may impact results' generalisability. Some studies reported on only a few subjects and appeared to be driven by one or more enthusiastic healthcare professionals. This is evident in a paper by Pesut and colleagues who described the experiences of 25 older adults and their families in rural Canada, receiving bi-weekly home visits from an experienced nurse navigator over a 2-year period [74]. It is likely that without the involvement of similarly motivated individuals, such positive outcomes may not be reproduceable elsewhere.

Trying to unpick the contribution of each component of a complex intervention and establishing cause and effect can be problematic. These complexities were illustrated in the Marie Curie Delivering Choice Programme in rural Somerset, England, which comprised a telephone advice line, a nurse-led hospital-based discharge service, 22 coordination centres delivering multiagency care, and an electronic register to record advanced care wishes [56]. Using service evaluation to identify the effect of each component in reducing hospital bed days was difficult. Similar challenges have been encountered across most other studies.

The present study has several research limitations. We did not appraise the methodological quality of the selected studies. Further, a degree of judgement of what to include was required. For example, we did not explore general initiatives seeking to educate and advance the concept of palliative care. Such efforts were considered unlikely to have a measurable effect on hospital utilisation. Because of the search terms used and initiatives' heterogeneous nature, it is possible that we may have missed important developments, especially those referred to in non-English publications. Our experience is that relevant data is sometimes buried in less accessible reports, and those studies often lack methodological detail. Also, whereas the five-year search period was selected to make this project manageable and was based on the assumption that earlier promising initiatives would be carried over into newer publications, the timeframe was relatively short. Finally, our research does not address quality of care outside hospital, or whether reducing bed days actually saves health systems money or simply transfers costs elsewhere. All of these issues may have influenced our conclusions. 


\section{Conclusions}

There is much innovation happening to improve end of life care. Evidence as to whether it reduces inappropriate or non-beneficial hospital utilisation is limited, sometimes contradictory and of variable quality. Many people working in palliative care are convinced that what they are doing can benefit patients and families through a reduction in unnecessary and burdensome end-of-life hospital admissions but, do not have robust evidence to prove it. Where success is claimed, we still know little about why an initiative worked and how it might be successfully transposed elsewhere. It is worth restating that not all bed days are 'bad' or unwanted by patients and families.

As so often in palliative care, further research is required. A notable example is the area of ambulance and paramedic education. It is hoped that the ongoing quantitative and qualitative HOLISTIC study, which looks at patient journeys toward the end of life by mapping Hospital Episode Statistics data against stakeholder interviews, may provide further insights.

\begin{abstract}
Abbreviations
HOLISTIC: HOspice-Led Innovations Study To Improve Care project; INTERACT: Interventions to Reduce Acute Care Transfers; NHS: National Health Service; NSCLC: Non-Small Cell Lung Cancer; PEPS: Partnership for Excellence in Palliative Support; PREFER: Palliative advanced home caRE and heart FailurE caRe; RCT: Randomised Control Trial; SPA: Single Point of Access
\end{abstract}

\section{Acknowledgements}

Dr. Sarah Russell and Suzanne Stephenson at Hospice UK provided methodological advice.

Dr. Yvonne Anderson provided methodological advice. Dr. Sophia Whitman, Dr. Allon Hazan, Ananya Malladi and Esther Fash at Stgilesmedical London \& Berlin supported the document search, publication review and early drafts of this manuscript. Tony Docker provided early project management. Sarah Stinnissen and Harry O'Connor provided editing support. All of the above were employees or associates of Stgilesmedical London \& Berlin (www. stgmed.com).

Dr. Rodrigo Cerda, Dr. Melvin Mezue, Natasha Stone and Oliver Munn at McKinsey \& Company provided pro bono project support.

The following members of the HOLISTIC Steering Committee not listed as authors provided general advice on this project:

Alan Barron, Wigan \& Leigh Hospice, Wigan, UK.

Christine Gibbon, Hospice UK, London, UK.

Lorna Langdon, NHS England, Leeds, UK.

Nicola Spencer, NHS England, Leeds, UK.

Dr. Caroline Stirling, UCL Partners, London, UK

Linda Wilson, NHS England, Leeds, UK.

\section{Authors' contributions}

Ros Taylor: Contributed to the project concept and manuscript writing. Provided background knowledge and reviewed and approved the text. Jonathan Ellis: Project lead. Contributed to the project concept. Provided background knowledge and reviewed and approved the text. Wei Gao: Provided background knowledge, some content and reviewed and approved the text. Liz Searle: Provided background knowledge, some content and reviewed and approved the text. Kate Heaps: Provided background knowledge, some content and reviewed and approved the text. Robert Davies: Substantially contributed to research, manuscript writing and data interpretation. Critically revised/approved the version to be published. Claire Hawksworth: Substantially contributed to research, manuscript writing and data interpretation. Critically revised/approved the version to be published. Angela Garcia-Perez: Substantially contributed to research, manuscript writing and data interpretation. Critically revised/approved the version to be published. Giles Colclough: Contributed to the project concept and manuscript writing. He provided background knowledge and reviewed and approved the text. Steven Walker: Original instigator. Substantially contributed to manuscript writing and data interpretation. Critically revised/approved the version to be published. Bee Wee: Project sponsor. Contributed to the project concept. Provided background knowledge, some content and reviewed and approved the text. All authors have read and approved the manuscript.

\section{Funding}

The HOLISTIC Study is funded by NHS England and is being delivered by HOSPICE UK with the support of Stgilesmedical London \& Berlin (www. stgmed.com) and McKinsey \& Company. The development of this review was a separate project which received no funding and was undertaken on a pro bono basis by all participants.

\section{Availability of data and materials}

This manuscript relies on the documents listed under References. All other material is available upon request from the corresponding author.

Ethics approval and consent to participate

Not applicable.

\section{Consent for publication}

Not applicable.

\section{Competing interests}

There are no financial conflicts of interest. The authors are involved in the ongoing HOLISTIC research which was initiated by NHS England. Professor Bee Wee is National Clinical Director of End of Life Care, NHS England.

\section{Author details}

${ }^{1}$ Hospice UK, London, UK. ${ }^{2}$ Cicely Saunders Institute, London, UK. ${ }^{3}$ Keech Hospice Care, Luton, UK. ${ }^{4}$ Greenwich \& Bexley Hospice, London, UK. ${ }^{5}$ Stgilesmedical Ltd, The Vestry House, St Giles High Street, London WC2H 8LG, UK. ${ }^{6}$ Stgilesmedical GmbH, Berlin, Germany. ${ }^{7}$ McKinsey \& Company, London, UK. ${ }^{8}$ Harris Manchester College, University of Oxford, Oxford, UK. ${ }^{9}$ Sir Michael Sobell House, Oxford University Hospitals NHS Foundation Trust, Oxford, UK.

Received: 3 September 2019 Accepted: 12 February 2020

Published online: 27 February 2020

References

1. Cardona-Morrell M, Kim JCH, Brabrand M, et al. What is inappropriate hospital use for elderly people near the end of life? A systematic review. Eur J Intern Med. 2017:42:39-50.

2. Smith S, Brick A, O'Hara $\mathrm{S}$, et al. Evidence on the cost and cost-effectiveness of palliative care: a literature review. Palliat Med. 2014;28:130-50.

3. Ahearn DJ, Nidh N, Kallat A, et al. Offering older hospitalised patients the choice to die in their preferred place. Postgrad Med J. 2013;89:20-4.

4. Cardona-Morrell M, Kim J, Turner RM, et al. Non-beneficial treatments in hospital at the end of life: a systematic review on the extent of the problem. Int J Qual Health Care. 2016;28:456-69.

5. Gardiner C, Ward S, Gott M, et al. Economic impact of hospitalisations among patients in the last year of life: an observational study. Palliat Med. 2014:28:422-9.

6. NHS England. Funding the right care and support for everyone. Creating a fair and transpararent funding system: the final report of the palliative care funding review. J Pain Palliat Care Pharmacother. 2011;25:362-4.

7. Virdun C, Luckett T, Davidson PM, et al. Dying in the hospital setting: a systematic review of quantitative studies identifying the elements of endof-life care that patients and their families rank as being the most important. Palliat Med. 2015;29:774-96.

8. Gomes B, Higginson IJ. Where people die (1974-2030): past trends, future projections and implications for care. Palliat Med. 2008;22:33-41.

9. Department of Health. End of Life Care Strategy: promoting high quality care for all adults at the end of life. Report. London: National Health Service; 2008. 
10. Office for National Statistics. National survey of bereaved people (VOICES): England, 2015. London: Report, NHS England; 2016.

11. England NHS. Actions for end of life care: 2014-2016. London: Report, NHS England; 2014

12. National Palliative and End of Life Care Partnership. Ambitions for palliative and end of life care: a national framework for local action 2015-20. Report. London: NHS England; 2015.

13. Australian Department of Health. Supporting Australians to live well at the end of life: National Palliative Care Strategy 2010. Canberra: Report, Australian Department of Health; 2010.

14. Pollock K. Is home always the best and preferred place of death? BMJ. 2015; 351:h4855.

15. Hoare S, Morris ZS, Kelly MP, et al. Do patients want to die at home? A systematic review of the UK literature, focused on missing preferences for place of death. PLoS One. 2015;10:e0142723.

16. Gomes B, Calanzani N, Higginson IJ. Local preferences and place of death in regions within England 2010. UK: Report, Cicely Saunders International; 2011.

17. Broad JB, Gott M, Kim H, et al. Where do people die? An international comparison of the percentage of deaths occurring in hospital and residential aged care settings in 45 populations, using published and available statistics. Int J Public Health. 2013;58:257-67.

18. Gardiner C, Ingleton C, Ryan T, et al. What cost components are relevant for economic evaluations of palliative care, and what approaches are used to measure these costs? A systematic review. Palliat Med. 2017;31:323-37.

19. Bardsley M, Georghiou T, Spence R, et al. Factors associated with variation in hospital use at the end of life in England. BMJ Support Palliat Care. 2016;0:1-8.

20. Polder JJ, Barendregt JJ, Van Oers H. Health care costs in the last year of life-the Dutch experience. Soc Sci Med. 2006;63:1720-31.

21. National Institute for Health Care Excellence. Emergency and acute medical care in over 16s: service delivery and organisation. Report. Manchester: National Institute for Health Care Excellence; 2018.

22. The Balance of Care Group. Identifying alternatives to hospital, for people at the end of life 2008. Report. London: National Audit Office; 2008.

23. Abel J, Rich A, Griffin T, et al. End-of-life care in hospital: a descriptive study of all inpatient deaths in 1 year. Palliat Med. 2009;23:616-22.

24. Durand A, Bourgeon S, Lam A, et al. Cost-effective commissioning of end of life care. User guide for the end of life economic analysis tool. London: Report, Public Health England; 2017.

25. Curtis LA, Burns A. Unit costs of health and social care 2017. Report. UK: University of Kent; 2017.

26. Hawksworth C. The HOLISTIC study: hospice-led innovations study to improve care: progress report. Report. London: Hospice UK; 2017.

27. Sue Ryder Ltd. Partnership for Excellence in Palliative Support (PEPS). Report. Suffolk: Sue Ryder; 2012.

28. Garden G, Green S, Pieniak S, et al. The Bromhead care home service: the impact of a service for care home residents with dementia, on hospital admission and dying in preferred place of care. Clin Med. 2016;16:114-8.

29. Livingston G, Lewis-Holmes E, Pitfield C, et al. Improving the end-of-life for people with dementia living in a care home: an intervention study. Int Psychogeriatr. 2013;25:1849-58

30. Rantz MJ, Flesner MK, Franklin J, et al. Better care, better quality: reducing avoidable hospitalizations of nursing home residents. J Nurs Care Qual. 2015;30:290-7

31. Chapman M, Johnston N, Lovell C, et al. Avoiding costly hospitalisation at end of life: findings from a specialist palliative care pilot in residential care for older adults. BMJ Support Palliat Care. 2016;8:102-9.

32. Kane RL, Huckfeldt $P$, Tappen $R$, et al. Effects of an intervention to reduce hospitalizations from nursing homes: a randomized implementation trial of the INTERACT program. JAMA Intern Med. 2017;177:1257-64.

33. Ouslander JG, Bonner A, Herndon $L$, et al. The interventions to reduce acute care transfers (INTERACT) quality improvement program: an overview for medical directors and primary care clinicians in long term care. J Am Med Dir Assoc. 2014;15:162-70.

34. Ltd SQW, Social Care Institute Excellence. Evaluation of Sutton homes of care vanguard. Report. London: Sutton Clinical Commissioning Group; 2018.

35. Maniatopoulos G, Hunter D, Erskine J, et al. North east vanguards Programme: final evaluation. Report. UK: Durham University, Newcastle University and Northumbria University; 2017.

36. Hex N, Turner EE, Wright D, et al. Economic analysis of care homes: new models of care vanguard. Report. York: York Health Economics Consortium; 2018
37. Grabowski DC, O'Malley AJ. Use of telemedicine can reduce hospitalizations of nursing home residents and generate savings for medicare. Health Aff (Millwood). 2014;33:244-50.

38. Wong $\mathrm{R}$, Tan PT, Seow $\mathrm{YH}$, et al. Home-based advance care programme is effective in reducing hospitalisations of advanced heart failure patients: a clinical and healthcare cost study. Ann Acad Med Singap. 2013;42:466-71.

39. Lustbader D, Mudra M, Romano C, et al. The impact of a home-based palliative care program in an accountable care organization. J Palliat Med. 2017;20:23-8.

40. Spilsbury K, Rosenwax L, Arendts G, et al. The impact of community-based palliative care on acute hospital use in the last year of life is modified by time of death, age and underlying cause of death. A population-based retrospective cohort study. PLoS One. 2017;12:e0185275.

41. Seow H, Brazil K, Sussman J, et al. Impact of community based, specialist palliative care teams on hospitalisations and emergency department visits late in life and hospital deaths: a pooled analysis. BMJ. 2014;348:g3496.

42. Seow H, Barbera L, Pataky R, et al. Does increasing home care nursing reduce emergency department visits at the end of life? A population-based cohort study of cancer decedents. J Pain Symptom Manag. 2016;51:204-12.

43. Gagnon B, Nadeau L, Scott S, et al. The association between home palliative care services and quality of end-of-life care indicators in the province of Quebec. J Pain Symptom Manag. 2015;50:48-58.

44. lupati S, Ensor B. Do community hospice programmes reduce hospitalisation rates in patients with advanced chronic obstructive pulmonary disease? Int Med J. 2016;46:295-300.

45. Rosenwax L, Spilsbury K, Arendts G, et al. Community-based palliative care is associated with reduced emergency department use by people with dementia in their last year of life: a retrospective cohort study. Palliat Med. 2015;29:727-36.

46. Alonso-Babarro A, Astray-Mochales J, Dominguez-Berjon F, et al. The association between in-patient death, utilization of hospital resources and availability of palliative home care for cancer patients. Palliat Med. 2013;27:68-75.

47. McNamara BA, Rosenwax LK, Murray K, et al. Early admission to communitybased palliative care reduces use of emergency departments in the ninety days before death. J Palliat Med. 2013;16:774-9.

48. Ranganathan A, Dougherty M, Waite D, et al. Can palliative home care reduce 30-day readmissions? Results of a propensity score matched cohort study. J Palliat Med. 2013;16:1290-3.

49. Cassel BJ, Kerr KM, McClish DK, et al. Effect of a home-based palliative care program on healthcare use and costs. J Am Geriatr Soc. 2016;64:2288-95.

50. Tan WS, Lee A, Yang SY, et al. Integrating palliative care across settings: a retrospective cohort study of a hospice home care programme for cancer patients. Palliat Med. 2016;30:634-41.

51. Riolfi M, Buja A, Zanardo C, et al. Effectiveness of palliative home-care services in reducing hospital admissions and determinants of hospitalization for terminally ill patients followed up by a palliative home-care team: a retrospective cohort study. Palliat Med. 2014;28:403-11.

52. Lukas L, Foltz C, Paxton H. Hospital outcomes for a home-based palliative medicine consulting service. J Palliat Med. 2013;16:179-84.

53. Goldenheim A, Oates D, Parker V, et al. Rehospitalization of older adults discharged to home hospice care. J Palliat Med. 2014;17:841-4.

54. Kerr CW, Donohue KA, Tangeman JC, et al. Cost savings and enhanced hospice enrollment with a home-based palliative care program implemented as a hospice-private payer partnership. J Palliat Med. 2014;17:1328-35.

55. Pouliot K, Weisse CS, Pratt DS, et al. First-year analysis of a new, home-based palliative care program offered jointly by a community hospital and local visiting nurse service. Am J Hosp Palliat Care. 2017;34:166-72.

56. Purdy S, Lasseter G, Griffin T, et al. Impact of the Marie Curie Cancer Care delivering choice Programme in Somerset and North Somerset on place of death and hospital usage: a retrospective cohort study. BMJ Support Palliat Care. 2015:5:34-9.

57. Hoek PD, Schers HJ, Bronkhorst EM, et al. The effect of weekly specialist palliative care teleconsultations in patients with advanced cancer-a randomized clinical trial. BMC Med. 2017;15:119.

58. Bakitas MA, Tosteson TD, Li Z, et al. Early versus delayed initiation of concurrent palliative oncology care: patient outcomes in the ENABLE II randomized controlled trial. J Clin Oncol. 2015;33:1438-45.

59. Kirk $A$, Crompton $P$, Knighting $K$, et al. Paramedics and their role in end-oflife care: perceptions and confidence. J Paramed Pract. 2017;9:71-9.

60. Ferrell B, Sun V, Hurria A, et al. Interdisciplinary palliative care for patients with lung cancer. J Pain Symptom Manag. 2015;50:758-67. 
61. Benthien KS, Nordly M, von Heymann-Horann A, et al. Causes of hospital admissions in Domus: a randomized controlled trial of specialized palliative cancer care at home. J Pain Symptom Manag. 2017;55:728-36.

62. Blackhall LJ, Read P, Stukenborg G, et al. CARE track for advanced cancer: impact and timing of an outpatient palliative care clinic. J Palliat Med. 2016; 19:57-63.

63. Jang RW, Krzyzanowska MK, Zimmermann C, et al. Palliative care and the aggressiveness of end-of-life care in patients with advanced pancreatic cancer. J Natl Cancer Inst. 2015;107.

64. Morita T, Miyashita M, Yamagishi A, et al. Effects of a programme of interventions on regional comprehensive palliative care for patients with cancer: a mixed-methods study. Lancet Oncol. 2013;14:638-46.

65. Youens D, Moorin R. The impact of community-based palliative care on utilization and cost of acute care hospital services in the last year of life. J Palliat Med. 2017:20:736-44.

66. May P, Garrido MM, Cassel JB, et al. Cost analysis of a prospective multi-site cohort study of palliative care consultation teams for adults with advanced cancer: where do cost-savings come from? Palliat Med. 2017;31:378-86.

67. Rogers JG, Patel CB, Mentz RJ, et al. Palliative care in heart failure: the PALHF randomized, controlled clinical trial. J Am Coll Cardiol. 2017;70:331-41.

68. Brannstrom M, Boman K. Effects of person-centred and integrated chronic heart failure and palliative home care. PREFER: a randomized controlled study. Eur J Heart Fail. 2014;16:1142-51.

69. Chan KY, Cheng HW, Yap DY, et al. Reduction of acute hospital admissions and improvement in outpatient attendance by intensified renal palliative care clinic follow-up: the Hong Kong experience. J Pain Symptom Manag. 2015:49:144-9

70. Horton $\mathrm{R}$, Rocker $\mathrm{G}$, Dale A, et al. Implementing a palliative care trial in advanced COPD: a feasibility assessment (the COPD IMPACT study). J Palliat Med. 2013;16:67-73.

71. Hussain J, Adams D, Campbell C. End-of-life care in neurodegenerative conditions: outcomes of a specialist palliative neurology service. Int J Palliat Nurs. 2013;19:162-9.

72. Wu FM, Newman JM, Lasher A, et al. Effects of initiating palliative care consultation in the emergency department on inpatient length of stay. $J$ Palliat Med. 2013;16:1362-7.

73. Desrosiers T, Cupido C, Pitout E, et al. A hospital-based palliative care service for patients with advanced organ failure in sub-Saharan Africa reduces admissions and increases home death rates. J Pain Symptom Manag. 2014; 47:786-92.

74. Pesut B, Hooper B, Jacobsen M, et al. Nurse-led navigation to provide early palliative care in rural areas: a pilot study. BMC Palliat Care. 2017;16:37.

75. Basoor A, Doshi NC, Cotant JF, et al. Decreased readmissions and improved quality of care with the use of an inexpensive checklist in heart failure. Congest Heart Fail. 2013;19:200-6.

76. Hua M, Ma X, Morrison RS, et al. Association between the availability of hospital-based palliative care and treatment intensity for critically ill patients. Ann Am Thorac Soc. 2018;15:1067-74.

77. Horton JR, Morrison RS, Capezuti E, et al. Impact of inpatient palliative care on treatment intensity for patients with serious illnesses. J Palliat Med. 2016; 19:936-42.

78. Malia C, Upperton J. Innovating for improvement: a pilot project to develop and implement nurse-led beds for end of life patients within a hospice inpatient unit. Report. Leeds: St Gemma's Hospice; 2016.

79. Murtagh F. Can palliative care teams relieve some of the pressure on acute services? BMJ. 2014;348:g3693. https://doi.org/10.1136/bmj.g3693.

80. Candy B, Holman A, Leurent B, et al. Hospice care delivered at home, in nursing homes and in dedicated hospice facilities: a systematic review of quantitative and qualitative evidence. Int J Nurs Stud. 2011;48:121-33.

81. Finlay I, Higginson I, Goodwin D, et al. Palliative care in hospital, hospice, at home: results from a systematic review. Ann of Oncol. 2002:13:257-64.

82. Nwosu AC, Mayland CR, Mason S, et al. Patients want to be involved in end-of-life care research. BMJ Support Palliat Care. 2013;3:457.

\section{Publisher's Note}

Springer Nature remains neutral with regard to jurisdictional claims in published maps and institutional affiliations.

\section{Ready to submit your research? Choose BMC and benefit from:}

- fast, convenient online submission

- thorough peer review by experienced researchers in your field

- rapid publication on acceptance

- support for research data, including large and complex data types

- gold Open Access which fosters wider collaboration and increased citations

- maximum visibility for your research: over $100 \mathrm{M}$ website views per year

At BMC, research is always in progress.

Learn more biomedcentral.com/submissions 